\title{
Correlating Electrocatalytic Activities with Sulfur Species on Sulfur-doped Cobalt Oxide
}

Kaicai Fan ${ }^{\mathrm{a}, \dagger}$, Wentao Liang ${ }^{\mathrm{a}, \dagger}$, Zhijin Tan $^{\mathrm{a}}$, Mohammad Al-Mamun ${ }^{\mathrm{a}}$, Yemei Luan ${ }^{\mathrm{a}, \mathrm{b}}$, Yun Wang ${ }^{\mathrm{a}}$, Porun Liu ${ }^{\mathrm{a}, ~ *}$, Huijun Zhao ${ }^{\mathrm{a}, \text { * }}$

${ }^{a}$ Centre for Clean Environment and Energy, School of Environment and Science, Griffith University, Queensland, 4222, Australia

${ }^{\mathrm{b}}$ College of Textile and Garment, Hebei University of Science and Technology, Shijiazhuang 050018, China

*Email: h.zhao@griffith.edu.au,p.liu@griffith.edu.au. Tel: (+61)-7-55528261

\begin{abstract}
:
Metal chalcogenide related materials have demonstrated outstanding catalytic activities for numerous chemical reactions in energy conversion devices. However, the actual active species have not yet been fully identified, especially for triiodide reduction in dye-sensitized solar cells (DSSCs). We herein adopted a vapor-phase hydrothermal (VPH) approach to controllably create the sulfur dopants on the $\mathrm{Co}_{3} \mathrm{O}_{4}$ nanosheets surface for high-performance DSSCs with a best power conversion efficiency (PCE) of 8.86\%. More importantly, our XPS and electrochemical analysis confirm a close correlation between the $\mathrm{S}^{2-}$ species and the electrocatalytic activities.
\end{abstract}

Keywords: Vapor-phase hydrothermal approach; Sulfur doping; Triiodide reduction; Thin films; Energy storage and conversion.

$\dagger$ These authors contributed equally to the manuscript. 


\section{Introduction}

Unveiling the nature of the catalytically active sites and their roles in catalyzing chemical reactions has been one of the key goals in developing efficient electrocatalysts for high-performance energy conversion systems [1]. Take DSSCs as an example, a huge variety of robust counter electrode (CE) materials, especially metal chalcogenide related materials, have been developed that render excellent electrocatalytic performance towards the regeneration of oxidized redox couples $\left(\mathrm{I}^{-} / \mathrm{I}_{3}\right.$ electrolyte as a benchmark redox couple) [2-6]. However, the actual electrocatalytically active chalcogenide species on the electrocatalyst surface has not been fully understood probably due to the fact that the multivalent nature of sulfur element allows the easy transformation from one oxidation state to another [7]. Moreover, the polysulfur species with different atomic configurations (bridging, apical or terminal etc.) generated during the reaction complicates the identification and control of the sulfur species. In this regard, a sulfurization approach that is capable of controlling the sulfur species will provide a useful platform for the in-depth understanding of the correlation between sulfur speciation and the electrocatalytic activities.

Herein, we extend a facile in-situ vapor-phase hydrothermal (VPH) approach [8] to fabricate high-performance CE materials for DSSCs with a best power conversion efficiency (PCE, $\eta$ ) of $8.86 \%$. More importantly, the sulfur speciation on the surface during the doping process was carefully monitored and its close correlation with electrocatalytic activities was confirmed. Our results provide new insights in the structure-performance relationship that open up avenues for the design of highperformance electrocatalysts.

\section{Experimental}


$\mathrm{Co}_{3} \mathrm{O}_{4}$ nanosheets @FTO samples were prepared with cathodic electrodeposition of $\mathrm{Co}(\mathrm{OH})_{2}$ film in an electrolyte of $0.09 \mathrm{M} \mathrm{Co}\left(\mathrm{NO}_{3}\right)_{3}$ and $0.1 \mathrm{M} \mathrm{NaNO} \mathrm{Na}_{3}$ at $1 \mathrm{~mA} / \mathrm{cm}^{2}$, followed by pyrolysis in air at $400^{\circ} \mathrm{C}$. The samples were doped in a closed VPH reactor [9], where the $\mathrm{Co}_{3} \mathrm{O}_{4}$ film was held above the reactants $\left(\mathrm{Al}_{2} \mathrm{~S}_{3}(0.26 \mathrm{~g})\right.$ and $60 \mu \mathrm{L}$ water $)$ at various temperatures and with varied durations. The as-obtained $\mathrm{S}-\mathrm{Co}_{3} \mathrm{O}_{4}$ films were rinsed in $\mathrm{CS}_{2}$, ethanol and water prior to structural characterization or electrochemical tests. The details of materials, solar cell construction, characterizations and the experiment for optimal $\mathrm{Co}_{3} \mathrm{O}_{4}$ film thickness can be found in the supplementary information.

\section{Results and Discussion}
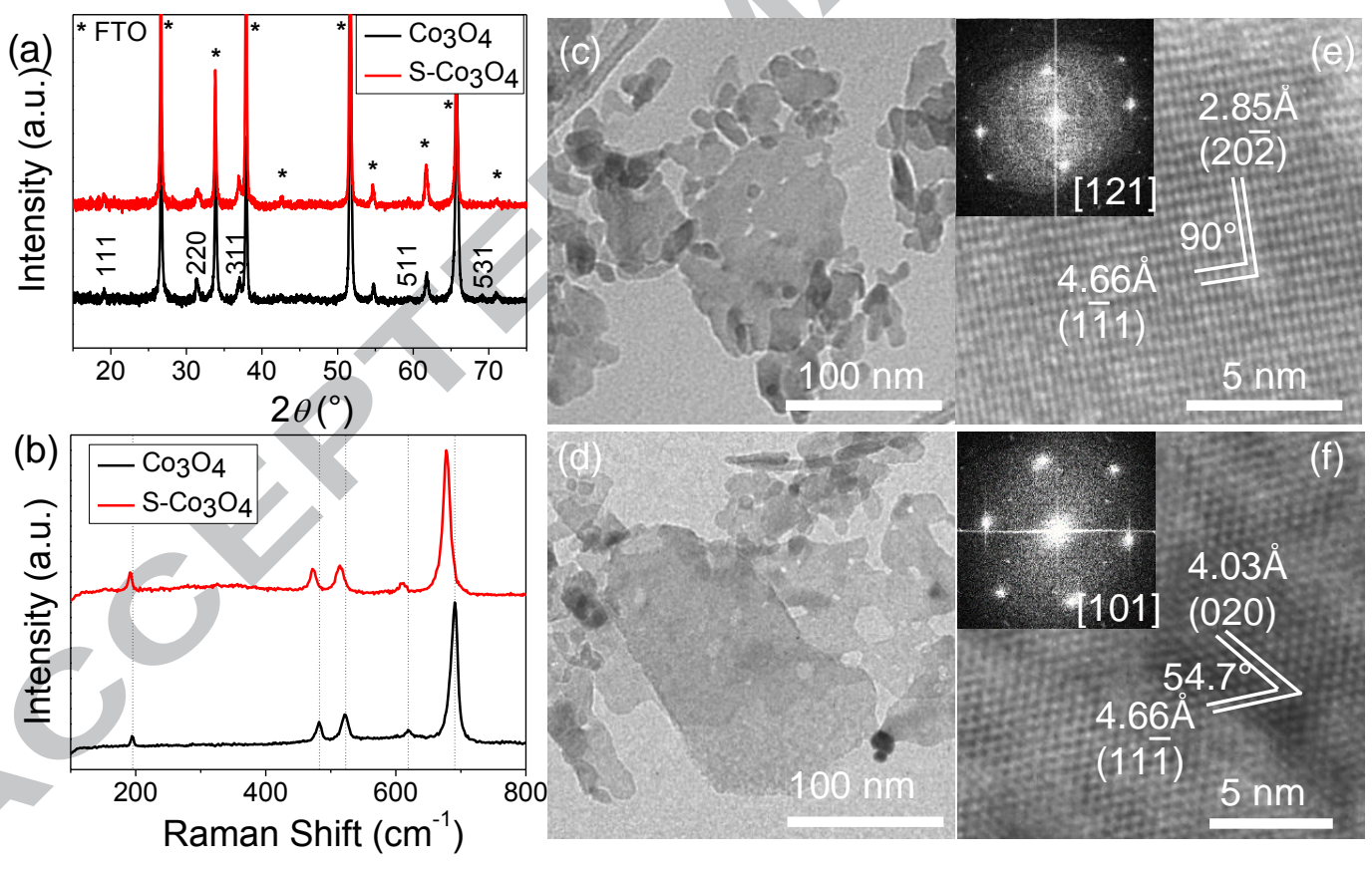

Figure 1 (a) XRD data, (b) Raman spectra, (c, d) TEM images, (e, f) HRTEM images of $\mathrm{Co}_{3} \mathrm{O}_{4}$ and $\mathrm{S}-\mathrm{Co}_{3} \mathrm{O}_{4}$ samples, respectively.

The XRD and Raman spectra of both $\mathrm{Co}_{3} \mathrm{O}_{4}$ and $\mathrm{S}-\mathrm{Co}_{3} \mathrm{O}_{4}$ samples (Figure $1 \mathrm{a}$ and 1b) are consistent with those of the spinel $\mathrm{Co}_{3} \mathrm{O}_{4}$ crystals. Notably, the Raman peaks of 
pristine $\mathrm{Co}_{3} \mathrm{O}_{4}$ sample have been red shifted after VPH doping treatment suggesting a decrease in the bond strength resulted from sulfur doping. TEM images of both samples exhibit a polycrystalline nanosheet structure (Figure 1c, d). The highresolution TEM (HRTEM) images (Figure 1e, f) confirmed lattice spacing of spinel $\mathrm{Co}_{3} \mathrm{O}_{4}$ crystal. These results implied the crystal structure of the $\mathrm{Co}_{3} \mathrm{O}_{4}$ has been well preserved after the VPH treatment. The submicron scaled $\mathrm{S}-\mathrm{Co}_{3} \mathrm{O}_{4}$ nanosheets provide a platform with sufficient electrocatalytic active sites and facilitate electron pathways for charge transfer.

The electrochemical properties of the samples prepared at different VPH temperatures was investigated. As the CV shown in Figure 2a, all samples manifest similar electrochemical characteristics with two pairs of redox peaks. Also, all samples demonstrate larger current density of reduction peaks $\left(\mathrm{I}_{\mathrm{pc} 1}\right)$ and smaller peak-to-peak separation potential difference $\left(E_{p p}=E_{p a 1}-E_{p c 1}\right.$, see supplementary information) at negative potential range compared to the commercial Pt electrode, confirming their excellent electrocatalytic activities. This is also reflected in Tafel polarization plots (Figure 2b), showing larger exchange current densities $\left(J_{o}\right)$ than Pt electrode. As shown in the EIS data (Figure 2c, Table 1), the best value was recorded using a $\mathrm{S}-\mathrm{Co}_{3} \mathrm{O}_{4}$ sample prepared at $90^{\circ} \mathrm{C}$ showing an $\mathrm{R}_{\mathrm{CT}}$ of $2.03 \Omega \mathrm{cm}^{2}$, marginally larger than that of Pt electrode $\left(2.00 \Omega \mathrm{cm}^{2}\right)$. The measured photovoltaic performances of the DSSCs with the $\mathrm{S}-\mathrm{Co}_{3} \mathrm{O}_{4} \mathrm{CEs}$ (Figure $2 \mathrm{~d}$ and Table 1) have confirmed an improved performance compared to $\mathrm{Co}_{3} \mathrm{O}_{4}$ samples [8]. The open-circuit voltage $\left(V_{o c}\right)$ values of all DSSCs were $\sim 0.71 \mathrm{~V}$, close to the benchmark Pt CE $(0.73 \mathrm{~V})$. Moreover, the values of fill factors $(F F)$ for the DSSCs with CE prepared at $90^{\circ} \mathrm{C}$ measured 0.68, higher than the Pt $\mathrm{CE}$, and the 
short-circuit current density $\left(J_{s c}\right)$ was the highest. These lead to a PCE of $8.86 \%$, which is marginally inferior to the one with a Pt CE (9.00\%) yet higher than most of published cobalt sulfide related CEs (Table S2).

(a)

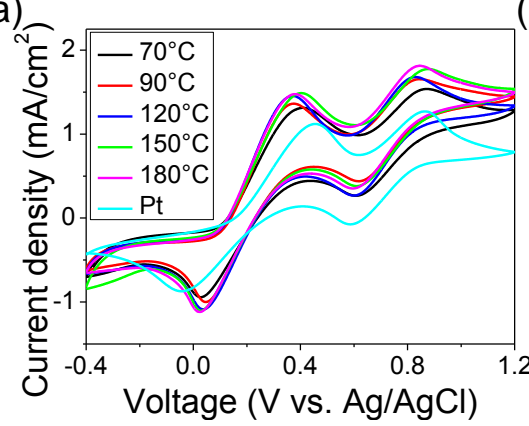

(b)

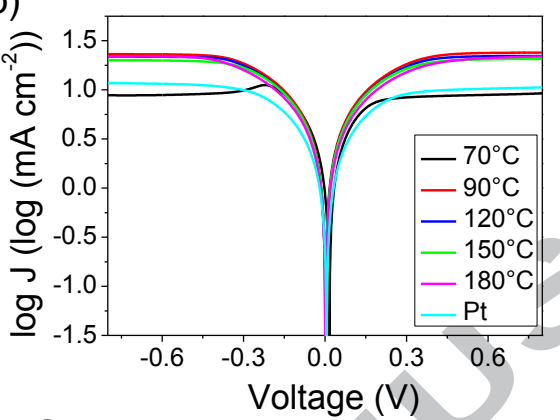

(c)

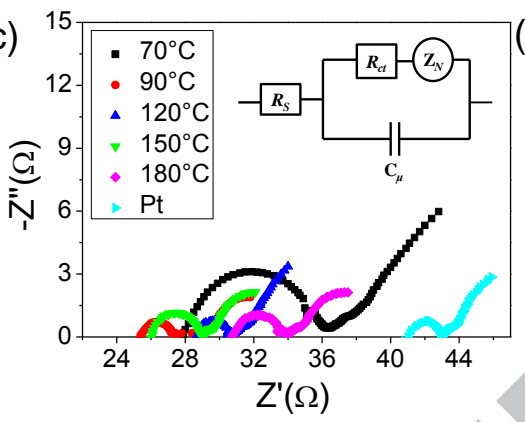

(d)

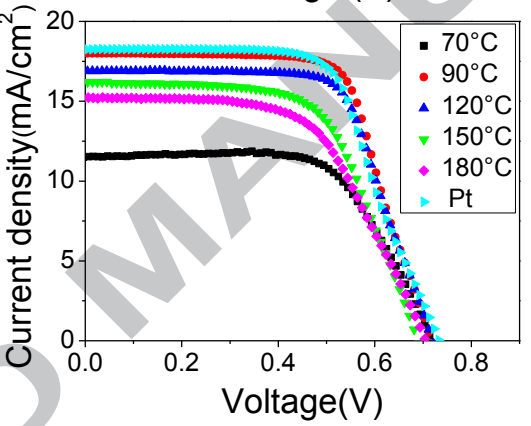

Figure 2 (a) CVs, (b) Tafel polarization curves, (c) EIS spectra and (d) $J$ - $V$ curves of the DSSCs, obtained using the $\mathrm{S}-\mathrm{Co}_{3} \mathrm{O}_{4}$ electrodes prepared at different temperatures.

Table 1 Photovoltaic parameters of the DSSCs and the EIS data of the electrodes prepared at different VPH temperatures.

The survey XPS spectra of the $\mathrm{S}-\mathrm{Co}_{3} \mathrm{O}_{4}$ obtained at $90{ }^{\circ} \mathrm{C}$ for different durations (10 min - 720 min, Figure S4) confirms a gradual transition of the

\begin{tabular}{|c|c|c|c|c|c|c|c|}
\hline Sample & $\begin{array}{l}\text { VPH } \\
\text { temperature }\left({ }^{\circ} \mathrm{C}\right)\end{array}$ & $\begin{array}{l}\boldsymbol{J}_{S C} \\
\left(\mathrm{~mA} / \mathrm{cm}^{2}\right)\end{array}$ & $\begin{array}{l}V_{O C} \\
(\mathrm{~V})\end{array}$ & $F F$ & $\begin{array}{l}\boldsymbol{\eta} \\
(\%)\end{array}$ & $\begin{array}{l}\boldsymbol{R}_{S} \\
(\Omega)\end{array}$ & $\begin{array}{l}\boldsymbol{R}_{C T} \\
(\Omega \\
\left.\mathrm{cm}^{2}\right)\end{array}$ \\
\hline 1 & 70 & 11.50 & 0.71 & 0.67 & 5.43 & 27.87 & 8.43 \\
\hline 2 & 90 & 18.00 & 0.72 & 0.68 & 8.86 & 25.36 & 2.03 \\
\hline 3 & 120 & 16.88 & 0.72 & 0.68 & 8.29 & 28.70 & 2.13 \\
\hline 4 & 150 & 16.17 & 0.69 & 0.62 & 6.91 & 26.01 & 3.00 \\
\hline 5 & 180 & 15.21 & 0.71 & 0.58 & 6.30 & 30.72 & 3.12 \\
\hline $\mathrm{Pt}$ & - & 18.23 & 0.73 & 0.65 & 9.00 & 41.00 & 2.00 \\
\hline
\end{tabular}


chemical bonding on the surface of the electrodes. Variation of $\mathrm{Co}, \mathrm{O}$ and $\mathrm{S}$ species (Figure 3c) confirms that VPH doping experienced two stages: in stage one $(0-180 \mathrm{~min})$, the $\mathrm{O}$ species are gradually replaced by the $\mathrm{S}$ species, in stage two (180 min onwards), the surface atomic concentrations become stabilized. These results strongly indicate the robustness of VPH approaches to effectively dope the metal oxide with sulfur atoms.
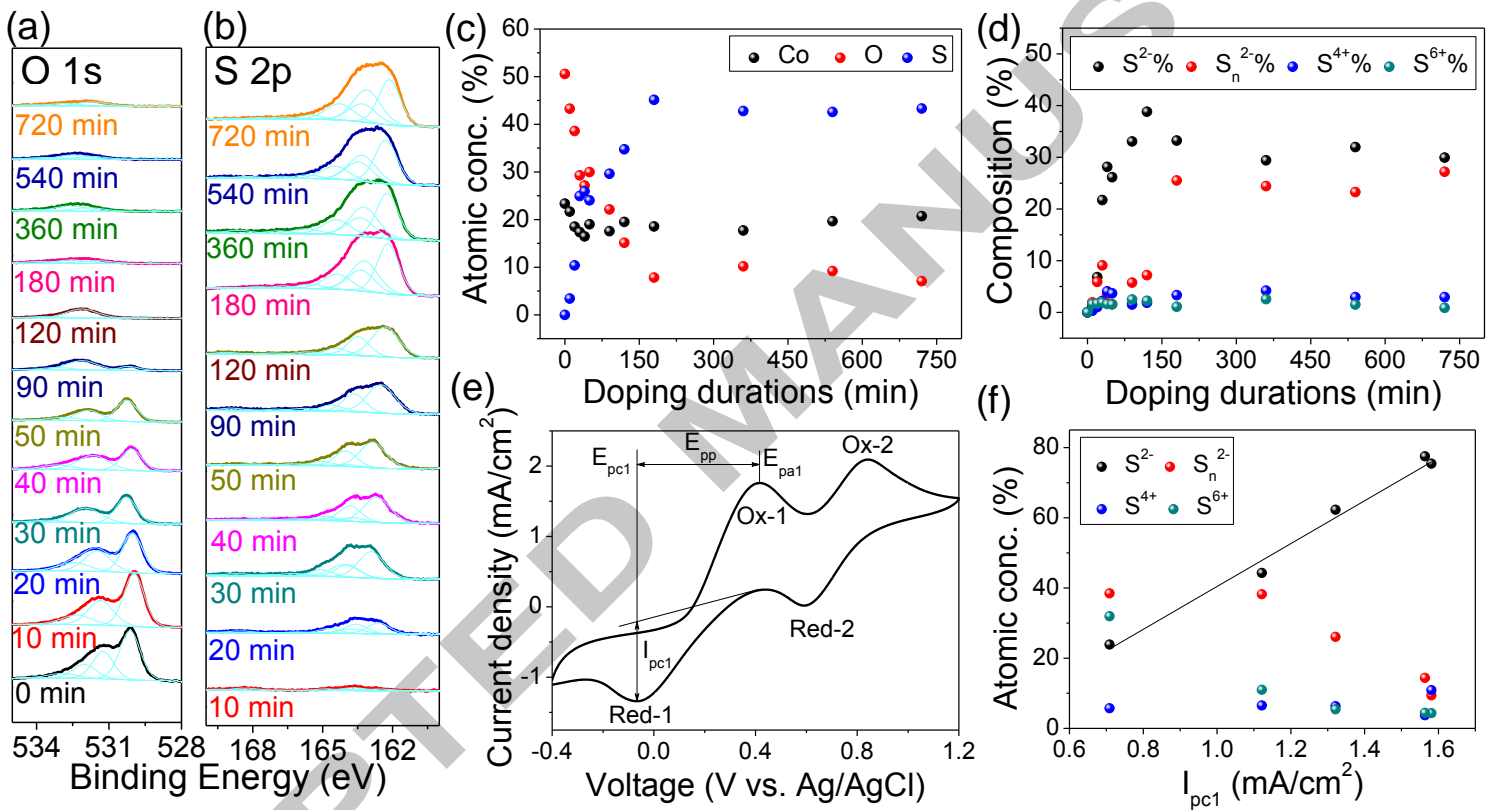

Figure 3 (a) O 1s, (b) S 2p XPS spectra, (c) variation of elements and (d) sulfur species of the $\mathrm{S}-\mathrm{CO}_{3} \mathrm{O}_{4}$ electrodes prepared with different VPH durations. (e) CVs of the S$\mathrm{Co}_{3} \mathrm{O}_{4}$ sample prepared with $20 \mathrm{~min} \mathrm{VPH}$ treatment. (f) Correlation between the extracted $\mathrm{I}_{\mathrm{pcl}}$ and sulfur species concentrations.

Also, the high-resolution scans of Co $2 \mathrm{p}_{3 / 2}$ spectra (Figure $\mathrm{S} 4 \mathrm{~b}$ ) show a gradual shift of a major peak centered at $779.9 \mathrm{eV}$ to $779.1 \mathrm{eV}$ (close to the $\mathrm{Co}_{3} \mathrm{~S}_{4}$ ) after $180 \mathrm{~min}$. Furthermore, the $\mathrm{O} 1 \mathrm{~s}$ spectra (Figure 3a) clearly show a constant decrease in lattice oxygen concentration $(530.1 \mathrm{eV})$ until completely 
eliminated after $180 \mathrm{~min}$. An increase in the intensity of the S species until 180 min was also observed. Overall, the XPS spectra indicate a rapid S doping process by substituting the lattice oxygen. The $S 2 p$ curves can be fitted into four pairs of $S 2$ p $1 / 2$ and $3 / 2$ doublets, i.e., $S^{6+}$ (sulfate), $S^{4+}$ (sulfite), $S_{n}{ }^{2-}$ (polysulfide) and $S^{2-}$ (sulfide) (Figure 3b). Relatively low sulfate and sulfite concentrations were detected, while there is a sharp increase in the concentration of sulfide species within $120 \mathrm{~min}$ of VPH treatment and the value becomes stable after $180 \mathrm{~min}$. Also, $\mathrm{S}_{\mathrm{n}}{ }^{2-}$ species concentration reached the stable value ( 25\%) after $180 \mathrm{~min}$. The overall elemental variations of all sulfur species agree well with the survey scans, confirming two VPH reaction stages.

It has been demonstrated that sulfur species on the metal sulfide surface may act as the catalytically active sites for the chemical reaction[10]. However, the catalytic active sites of the metal sulfide or sulfur doped metal oxide for triiodide reduction has not been confirmed. In this work, the $\mathrm{CV}$ curves of the $\mathrm{S}-\mathrm{Co}_{3} \mathrm{O}_{4}$ electrocatalysts in iodide/triiodide electrolyte were used to quantify their electrocatalytic activities. In particular, the magnitude of the cathodic peak current density (as $\mathrm{I}_{\mathrm{pc} 1}$ shown in Figure 3e) represents the electrocatalytic activity for triiodide reduction [11]. More attention was focused on the stage one of the VPH doping process where the sulfur concentration varies. Figure $3 f$ shows the correlation between the percentage of the different sulfur species in total sulfur and the $\mathrm{I}_{\mathrm{pc} 1}$ extracted from the corresponding CV curves (Figure S5). A good linear relationship $\left(y=62.19 x-21.664, R^{2}=0.9876\right)$ was observed between the $S^{2-}$ species percentage and the $\mathrm{I}_{\mathrm{pc} 1}$. This close correlation is consistent with our theoretical calculation results [8]. This finding is also in good agreement with the 
literature stating that $\mathrm{S}^{2-}$ rather than $\mathrm{S}_{\mathrm{n}}{ }^{2-}$ species dominated the cobalt sulfide samples which show outstanding electrocatalytic activity [12]. To the best of our knowledge, our findings provide the first direct experimental evidence showing the correlation between the sulfur species and electrocatalytic activities.

\section{Conclusions}

An in-situ VPH doping approach was adopted to heavily dope $\mathrm{Co}_{3} \mathrm{O}_{4}$ films for creation of electrocatalytically active sites. The best-performing DSSCs show an excellent PCE of $8.86 \%$, comparable to benchmark Pt electrode. Notably, our XPS and $\mathrm{CV}$ results unveiled a close correlation between the sulfide species (with lowest BE) on the $\mathrm{S}-\mathrm{Co}_{3} \mathrm{O}_{4}$ surface and the corresponding electrocatalytic activities. This finding improves the understanding of structure/performance relationships of metal chalcogenide related materials and will provide opportunities for energy conversion applications.

\section{Acknowledgements}

This work is support by Australian Research Council (DE170100607).

\section{References}

[1] J.K. Norskov, T. Bligaard, B. Hvolbaek, F. Abild-Pedersen, I. Chorkendorff, C.H. Christensen, Chem. Soc. Rev., 37 (2008) 2163-2171.

[2] Y. Sining, H. Anders, M. Tingli, Adv. Mater., 26 (2014) 6210-6237.

[3] M. Ye, X. Wen, M. Wang, J. Iocozzia, N. Zhang, C. Lin, Z. Lin, Mater. Today, 18 (2015) 155-162. 
[4] M. Al-Mamun, H. Zhang, P. Liu, Y. Wang, J. Cao, H. Zhao, RSC Adv., 4 (2014) 21277-21283.

[5] Y. Li, H. Wang, H. Zhang, P. Liu, Y. Wang, W. Fang, H. Yang, Y. Li, H. Zhao, Chem. Commun., 50 (2014) 5569-5571.

[6] M. Wang, A.M. Anghel, B. Marsan, N.-L. Cevey Ha, N. Pootrakulchote, S.M.

Zakeeruddin, M. Grätzel, J. Am. Chem. Soc., 131 (2009) 15976-15977.

[7] K. Nilsson, C.L. Peach, , Geochim. Cosmochim. Acta, 57 (1993) 3807-3813.

[8] Z. Tan, P. Liu, H. Zhang, Y. Wang, M. Al-Mamun, H.G. Yang, D. Wang, Z. Tang, H. Zhao, Chem. Commun., 51 (2015) 5695-5697.

[9] P. Liu, H. Zhang, H. Liu, Y. Wang, X. Yao, G. Zhu, S. Zhang, H. Zhao, J. Am. Chem. Soc., 133 (2011) 19032-19035.

[10] B. Lassalle-Kaiser, D. Merki, H. Vrubel, S. Gul, V.K. Yachandra, X. Hu, J. Yano, J. Am. Chem. Soc., 137 (2015) 314-321.

[11] C.-W. Kung, H.-W. Chen, C.-Y. Lin, K.-C. Huang, R. Vittal, K.-C. Ho, ACS Nano, 6 (2012) 7016-7025.

[12] S.-H. Chang, M.-D. Lu, Y.-L. Tung, H.-Y. Tuan, Large-Area Dye-Sensitized Solar Cells, ACS Nano, 7 (2013) 9443-9451. 


\section{Highlights}

- Vapor-phase hydrothermal (VPH) doping induces catalytic active sites on $\mathrm{Co}_{3} \mathrm{O}_{4}$

- Surface speciation of the elements during VPH doping process has been demonstrated

- $\mathrm{S}^{2-}$ dopant has close correlation with the corresponding catalytic activities 


\section{Accepted Manuscript}

Correlating Electrocatalytic Activities with Sulfur Species on Sulfur-doped Cobalt Oxide

Kaicai Fan, Wentao Liang, Zhijin Tan, Mohammad Al-Mamun, Yemei Luan, Yun Wang, Porun Liu, Huijun Zhao

PII: S0167-577X(18)31789-0

DOI: https://doi.org/10.1016/j.matlet.2018.11.029

Reference: MLBLUE 25251

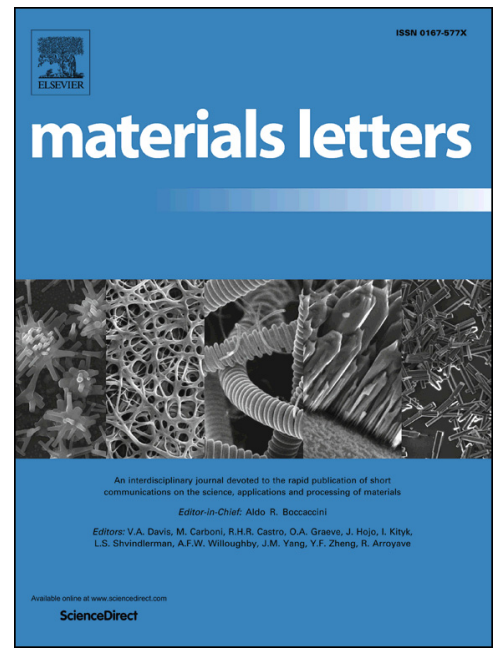

To appear in:

Materials Letters

Received Date:

12 July 2018

Revised Date: 17 October 2018

Accepted Date: 5 November 2018

Please cite this article as: K. Fan, W. Liang, Z. Tan, M. Al-Mamun, Y. Luan, Y. Wang, P. Liu, H. Zhao, Correlating Electrocatalytic Activities with Sulfur Species on Sulfur-doped Cobalt Oxide, Materials Letters (2018), doi: https:// doi.org/10.1016/j.matlet.2018.11.029

This is a PDF file of an unedited manuscript that has been accepted for publication. As a service to our customers we are providing this early version of the manuscript. The manuscript will undergo copyediting, typesetting, and review of the resulting proof before it is published in its final form. Please note that during the production process errors may be discovered which could affect the content, and all legal disclaimers that apply to the journal pertain. 